\title{
Blunt Trauma to the Penis Post Penile Augmentation Surgery: Case Report
}

\author{
James J. Elist1, Vaheh Shirvanian², Alireza Hosseini'3, Omead Mirgoli4 \\ ${ }^{1}$ Attending Staff, Cedars Sinai Medical Center, Los Angeles, CA, USA \\ ${ }^{2}$ Midtown Medical Center, Columbus, GA, USA \\ ${ }^{3}$ Iran University of Medical Sciences, Tehran, Iran \\ ${ }^{4}$ Ross University School of Medicine, Roseau, Commonwealth of Dominica \\ Email: drelist@gmail.com
}

Received 9 September 2014; revised 25 October 2014; accepted 7 November 2014

Academic editor: Sarel Halachmi, Israeli Institute of Technology, Israel

Copyright (C) 2014 by authors and Scientific Research Publishing Inc.

This work is licensed under the Creative Commons Attribution International License (CC BY).

http://creativecommons.org/licenses/by/4.0/

c) (i) Open Access

\begin{abstract}
Introduction: Blunt trauma to the penis is a rare but potentially serious injury that can occur by various mechanisms (e.g., kicks, accidents, sexual activity, and falls). The most common clinical presentation is sudden pain, swelling, and discoloration. Depending on the type and severity of injury, management can include conservative treatment or surgery, with the ultimate goal being the prevention of delayed complications. Case presentation: A 30-year-old male presented with penile pain, swelling, and redness as a result of blunt trauma to his penis 1 week after penile enhancement surgery using a subcutaneous soft silicone implant. Once the patient's blood pressure was stabilized, surgical management consisted of exploration with evacuation of a large hematoma and removal of the subcutaneous penile implant to avoid further perioperative and postoperative bleeding. Discussion: Postoperative bleeding is a risk factor associated with almost all types of surgical procedures, and its prevention is best achieved by identification and elimination of potential causes pre- and postoperatively. Hypertension is another risk factor for excessive postsurgical bleeding, particularly bleeding associated with prosthetic implant surgeries, and should be considered for any potential surgical patient. Conclusion: With penile prosthesis and implant surgery, hypertension is an especially serious risk factor. Early surgical management is warranted in cases involving a major hematoma and swelling. Even cases with minimal bleeding should be evaluated in a timely manner, with surgical treatment indicated, rather than watchful waiting, to prevent further damage to the penis.
\end{abstract}

\section{Keywords}

Penile Hematoma, Hypertension, Penile Implant, Penile Enlargement, Penile Enhancement 


\section{Surgery}

\section{Introduction}

Due to the increased risk of morbidity and mortality associated with postoperative bleeding in hypertensive patients, the pre- and postsurgical management of patients with high blood pressure is crucial [1]. Hypertension is a serious health issue that is prevalent in almost one-quarter of the general adult population worldwide [2]. Prevalence has been noted to increase with age and is higher in the general black population compared with other ethnicities [3]. In the United States, nearly 30\% of the population older than 20 years of age suffer from hypertension, with the prevalence nearly doubling in the black population compared with the white population [1] [4].

Blunt trauma to the male pelvis, groin, and external genitalia may cause injuries to the bladder, urethra, penis, and/or scrotum [5]. Compared with other pelvic injuries, penile trauma is rare because of the organ's anatomical position and inherent properties as a flexible external organ covered by loose skin. However, rare trauma to the male genitalia is a potentially serious injury and can occur by mechanisms such as falls, accidents, direct blunt or forceful trauma (e.g., kicks, sexual activity), burns, animal bites, gunshots, or self-mutilation. The usual clinical presentation, which includes pain and swelling, is often accompanied by significant negative psychological effects related to possible future organ dysfunction or aesthetic deformity [6] [7]. The appropriate management of penile trauma requires an early differential diagnosis between a torn tunica albuginea and extratunical or cavernosal hematoma. The former may warrant early surgical repair to prevent deformity and erectile dysfunction. For a cavernosal hematoma, a conservative approach such as expectant observation or possible evacuation for more severe cases is usually mandated [8]. Blunt trauma to the flaccid penis, with the cavernosal crura crushed against the pelvic bones, may produce extratunical or cavernosal hematomas with a usually intact thick fibrous tunica albuginea [8].

No single technique is appropriate for all types of penile injury, and different techniques must be used depending on the degree of damage. Regardless of type and severity, the primary goal of management of a penile injury should be correct diagnosis and an appropriate treatment modality to avoid complications and to achieve positive long-term sexual and cosmetic outcomes [1] [6].

\section{Case Presentation}

\subsection{Patient}

A 30-year-old black male presented with penile injury due to a fall with direct blunt force trauma to the penis. This occurred 1 week after penile augmentation surgery using a subcutaneous soft silicone implant (PeNuva; International Medical Devises, Los Angeles, CA, USA). The patient reported severe pain, inflammation, and swelling of his penis (Figure 1). Physical examination revealed hypertension, with blood pressure of 216/158 $\mathrm{mmHg}$, and massive penile swelling and multiple abrasions. The skin abrasions resulted from abrasive trauma and rupture of skin blisters on the dorsal and ventrolateral aspect of the penile shaft after repetitive use of a bedside urine bottle with sharp edges (Figure 2).

\subsection{Surgery}

After stabilizing the patient's blood pressure to avoid further perioperative and postoperative bleeding, surgical management consisted of exploration with evacuation of a large hematoma and removal of the subcutaneous penile implant (Figure 3). By entering through the incision line from the previous implant augmentation surgery, a large amount of coagulated blood was suctioned from the upper cavity of the intact soft silicone implant. The residual hematoma was completely removed by irrigation with normal saline and suctioning. No perforation, disruption, or tear was identified in the tunica. Implant removal was achieved by removal of the anchoring sutures located at the very distal tip of the implant. A thorough investigation revealed vascular injury as the sole source of bleeding, without tunical disruption. After meticulous hemostasis to prevent further bleeding, the penis was inverted, a JP drain was placed inside the implant cavity, and the skin was closed using non-absorbable sutures. Skin abrasions were then treated with the removal of the injured skin portions, and conservative therapy 


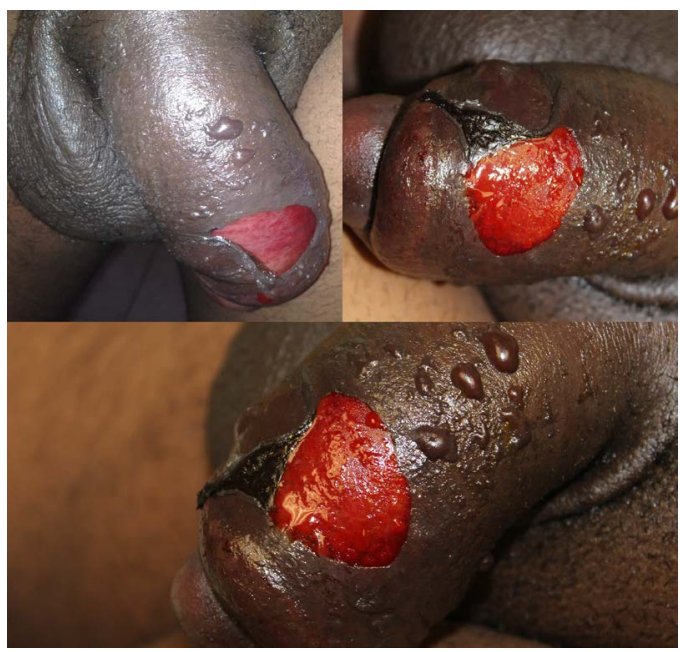

Figure 1. Diffuse penile swelling.

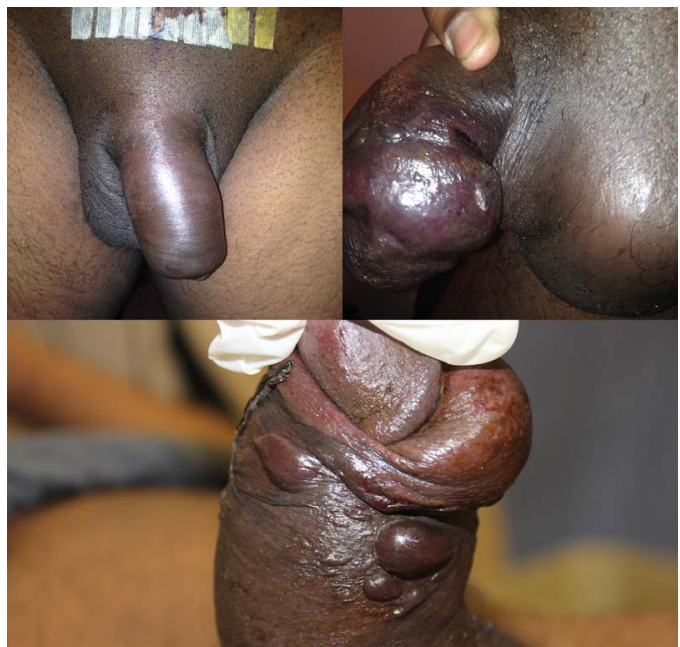

Figure 2. Skin erosions with blistering.

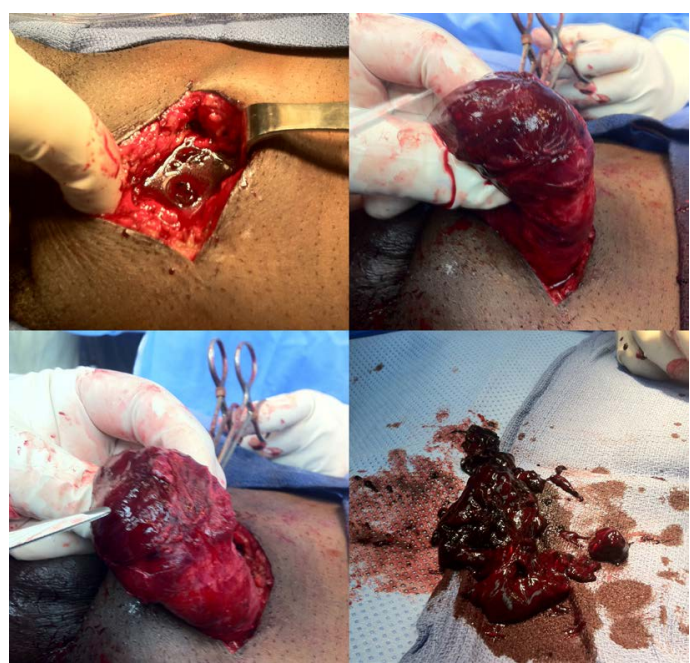

Figure 3. Exploration and evacuation of a massive hematoma. 
consisted of antibiotic application and non-adhesive dressing.

\section{Discussion}

More than 233 million surgical procedures are performed worldwide every year; of these, postsurgical complications occur in more than 7 million cases [9]. Consequently, complication prevention is of utmost medical interest, and standardized education and protocols for postoperative behavior are crucial. Common practice currently involves patient education through detailed verbal and written instructions regarding pre- and postoperative care. However, compliance with postoperative protocol can vary depending on many factors, in addition to the complexity of the instructions [10].

Bleeding after surgery is a risk factor associated with almost all types of surgical procedures, and its prevention is best achieved by identification and elimination of potential causes pre- and postoperatively [11].

Hypertension is a major risk factor that increases the propensity of patients to bleed excessively. This is especially true for patients postoperatively, when the traumatized tissue is still recovering [12]. Bleeding due to any mechanism is an even more serious complication in surgeries using a penile prosthesis or implant because of the risk of hematoma formation and subsequent infections [13] [14].

Several types of traumatic penile injury have been reported in the literature, with penile fractures being the most common [15]. Superficial injuries involving only the skin may indicate more profound damage to subdermal structures, which may require surgical investigation for assessment [16].

Injury to the penile vasculature includes rupture of the penile superficial dorsal vein, deep dorsal vein, dorsal artery, and nonspecific dartos bleeding [16]. Symptoms in vascular penile injuries are hematomas, swelling, and gradual detumescence. To prevent long-term complications associated with possible tunical tears, surgical exploration is advised [17]. In the case of traumatic vascular penile injury, as documented in our patient, a tunical tear was not noted, making surgical management somewhat less complicated [16]. Excavation of the hematoma is often crucial to relieve pressure on surrounding anatomical structures and to prevent other sequelae associated with long-term hematomal presence. Conservative treatment may result in complications including erectile dysfunction, penile curvature, abscess formation, or debilitating plaques with resultant longer periods of hospitalization and recovery in up to $29 \%$ of cases [18]-[20].

\section{Conclusion}

Hypertension is a major consideration and risk factor for any kind of penile surgery. With penile prosthesis and implant surgery, hypertension is an especially serious risk factor. Early surgical management is warranted in cases involving a major hematoma and swelling. Even cases involving minimal bleeding should be evaluated in a timely manner, with surgical treatment, rather than watchful waiting, to prevent further damage to the penis. We conclude that in cases involving preexisting conditions such as hypertension and vascular disease, the conservative treatment should be forgone in lieu of more aggressive surgical exploration and procedures.

\section{References}

[1] Tonolini, M. (2013) Urgent-Setting Magnetic Resonance Imaging Allows Triage of Extensive Penoscrotal Hematoma Following Blunt Trauma. Journal of Emergencies, Trauma and Shock, 6, 304-306. http://dx.doi.org/10.4103/0974-2700.120390

[2] Varon, J. and Marik, P.E. (2008) Perioperative Hypertension Management. Journal of Vascular Health and Risk Management, 3, 615-627.

[3] Svenson, J.E. and Repplinger, M. (2008) Hypertension in the ED: Still an Unrecognized Problem. Congestive Heart Failure, 26, 913-917. http://dx.doi.org/10.1016/j.ajem.2007.11.024

[4] Nesbitt, S. and Victor, R.G. (2004) Pathogenesis of Hypertension in African Americans. Congestive Heart Failure, 10, 24-29. http://dx.doi.org/10.1111/j.1527-5299.2004.02021.x

[5] He, J. and Whelton, P.K. (1997) Epidemiology and Prevention of Hypertension. Medical Clinics of North America, 81, 1077-1097. http://dx.doi.org/10.1016/S0025-7125(05)70568-X

[6] Lehnert, B.E., Sadro, C., Monroe, E. and Moshiri, M. (2014) Lower Male Genitourinary Trauma: A Pictorial Review. Emergency Radiology, 21, 67-74. http://dx.doi.org/10.1007/s10140-013-1159-Z

[7] Perovic, S.V., Djinovic, R.P., Bumbasirevic, M.Z., Santucci, R.A., Djordjevic, M.L. and Kourbatov, D. (2009) Severe Penile Injuries: A Problem of Severity and Reconstruction. BJU International, 104, 676-687. 
http://dx.doi.org/10.1111/j.1464-410X.2008.08343.x

[8] Hunter, S.R., Lishnak, T.S., Powers, A.M. and Lisle, D.K. (2013) Male Genital Trauma in sports. Clinics in Sports Medicine, 32, 247-254. http://dx.doi.org/10.1016/j.csm.2012.12.012

[9] Morey, A.F., Metro, M.J., Carney, K.J., Miller, K.S. and McAninch, J.W. (2004) Consensus on Genitourinary Trauma: External Genitalia. BJU International, 94, 507-515. http://dx.doi.org/10.1111/j.1464-410X.2004.04993.X

[10] Weiser, T.G., Makary, M.A., Haynes, A.B., Dziekan, G., Berry, W.R. and Gawande, A.A. (2009) Safe Surgery Saves Lives Measurement and Study Groups. Standardized Metrics for Global Surgical Surveillance. The Lancet, 14, 11131117. http://dx.doi.org/10.1016/S0140-6736(09)61161-2

[11] Albrecht, J.S., Gruber-Baldini, A.L., Hirshon, J.M., Brown, C.H., Goldberg, R., Rosenberg, J.H., Comer, A.C. and Furuno, J.P. (2014) Hospital Discharge Instructions: Comprehension and Compliance among Older Adults. Journal of General Internal Medicine, 29, 1491-1498. http://dx.doi.org/10.1007/s11606-014-2956-0

[12] Kurkar, A., Elderwy, A.A. and Orabi, E. (2014) False Fracture of the Penis: Different Pathology But Similar Clinical Presentation and Management. Urology Annals, 6, 23-26. http://dx.doi.org/10.4103/0974-7796.127015

[13] Nicolaisen, G.S., Melamud, A., Williams, R.D. and McAninch, J.W. (1983) Rupture of the Corpus Cavernosum: Surgical Management. Journal of Urology, 130, 917-919.

[14] Penson, D.F., Seftel, A.D., Krane, R.J., Frohrib, D. and Goldstein, I. (1992) The Hemodynamic Pathophysiology of Impotence Following Blunt Trauma to the Erect Penis. Journal of Urology, 148, 1171-1180.

[15] Morey, A.F., Rozanski, T.A. and Wein, A.J. (2007) Genital and Lower Urinary Tract Trauma. In: Wein, A.J., Kavoussi, L.R., Novick, A.C., Partin, A.W. and Peters, C.A., Eds., Campbell-Walsh Urology, 9th Edition, Chap 88, Saunders Elsevier, Philadelphia.

[16] Dagi, T.F. (2005) The Management of Postoperative Bleeding. Surgical Clinics of North America, 85, 1191-1213. http://dx.doi.org/10.1016/j.suc.2005.10.013

[17] Lip, G.Y. and Li-Saw-Hee, F.L. (1998) Does Hypertension Confer a Hypercoagulable State? Journal of Hypertension, 16, 913-916. http://dx.doi.org/10.1097/00004872-199816070-00003

[18] Richter, S. (2009) Avoiding Complications in Penile Prosthesis Surgery. International Society for Sexual Medicine Web Site. http://www.issm.info/news/review-reports/avoiding-complications-in-penile-prosthesis-surgery/

[19] Jack, G.D., Garraway, I., Reznichek, R. and Rajfer, J. (2004) Current Treatment Options for Penile Fractures. Reviews in Urology, 6, 114-120.

[20] Dicks, B., Bastuba, M. and Goldstein, I. (2013) Penile Revascularization-Contemporary Update. Asian Journal of Andrology, 15, 5-9. http://dx.doi.org/10.1038/aja.2012.146 
Scientific Research Publishing (SCIRP) is one of the largest Open Access journal publishers. It is currently publishing more than 200 open access, online, peer-reviewed journals covering a wide range of academic disciplines. SCIRP serves the worldwide academic communities and contributes to the progress and application of science with its publication.

Other selected journals from SCIRP are listed as below. Submit your manuscript to us via either submit@scirp.org or Online Submission Portal.
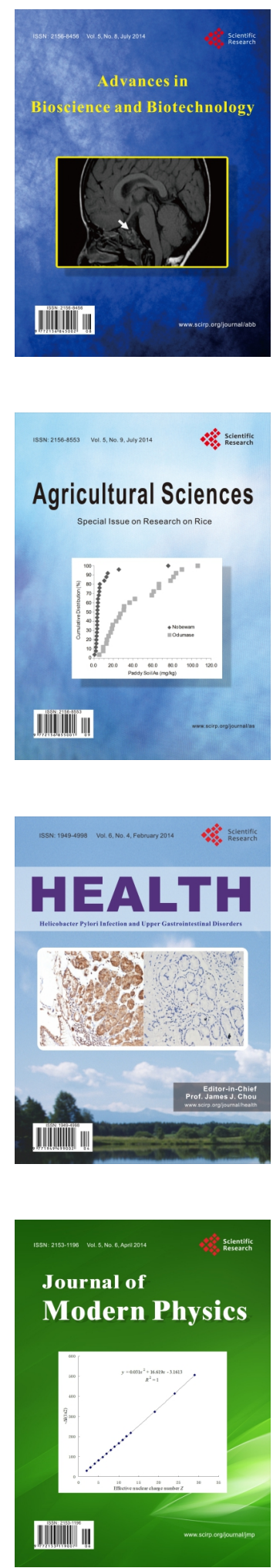
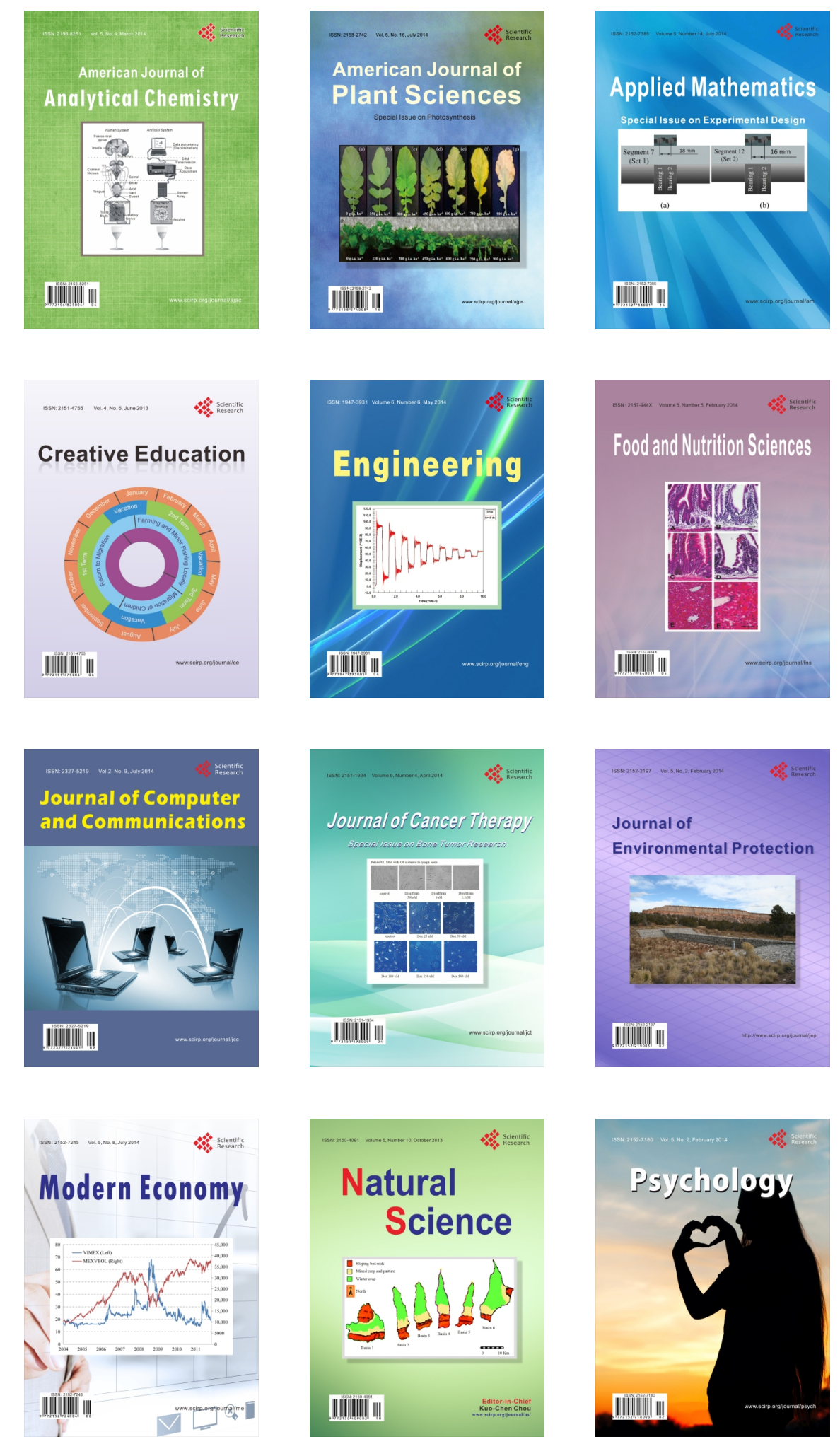